\title{
Report on the
}

Meeting of Presidents of
Mathematical Societies in
Maynooth, 14-15th April 2018

Sjoerd Verduyn Lunel, Secretary of the EMS, and Richard Elwes, EMS Publicity Officer

This is an abbreviated report of the Presidents' meeting, as several topics of discussion were also covered at the previous Rome Executive committee meeting (see page 5) or the subsequent Prague Council meeting (see page 3).

The meeting of the Presidents of EMS member societies is an annual society tradition. This year it gathered at Maynooth University in Ireland. Pavel Exner, EMS President and Chair of the meeting, welcomed the assembled company and thanked the organizers for the invitation to the Emerald Isle. After a tour de table in which the participants introduced themselves and their societies, Steve Buckley and Pauline Mellon, President and Vice-President (respectively) of our hosts the Irish Mathematical Society, delivered a presentation about their society. Founded at Trinity College Dublin in 1976, with a constitution based on that of the Edinburgh Mathematical Society, the Irish Mathematical Society holds regular mathematical events, including the Groups in Galway series which has run every spring since 1978, and an annual conference in September which covers both research and educational topics.

\section{EMS business}

The EMS President delivered a report on recent EMS activities. He reminded the meeting that ours is not principally a political body, and we cannot participate in all of the increasing number of public protests. At the same time, we must speak out when the life of our community is endangered. There is thus a balance to strike, and in line with this policy, he drew attention to an open letter of support for students arrested at Boğaziçi University in Turkey. (This can be found at www.bit.ly/2pUFPHu.)

The Chair asked the Presidents for help recruiting reviewers for the books section on the EMS webpage (www.euro-math-soc.eu/book-reviews), and recalled that members of the EMS have special benefits at www.Math Hire.org, a website to find and advertise mathematical jobs, that is supported by the EMS. This Autumn the EMS will evaluate its cooperation agreement with MathHire, and the Chair invited any feedback on this service.

The Chair reported on the EMS's spectrum of scientific activities, and encouraged member societies to prepare proposals for scientific events, such as Joint Mathematical Weekends and Summer Schools. He then spoke about the EMS standing committees in turn (see Council report for more details), requesting the cooperation of member societies in a few cases. Firstly, with regard to the Applied Mathematics Committee, the President drew attention to those H2020 calls where Mathematics can play a role, and referred to the webpage of EUMATHS-IN for further information. Secondly, a difficulty in raising money for the EMS's Committee for Developing Countries (CDC) is that increasing numbers of members pay their EMS dues through their local societies, rather than directly to the EMS, meaning they bypass the option to add a donation to the CDC. So the Chair requested that, where possible, this option also be advertised at the local level. Finally, the Chair passed a request from Roberto Natalini, Chair of the Raising Public Awareness committee (RPA), that the Presidents identify a contact for mathematical outreach activities within their own society, and send this information to the RPA.

Finally, the Chair informed the Presidents that the EMS has terminated its membership of Initiative for Science in Europe.

\section{Presentations}

The meeting then heard several presentations. First, Barbara Kaltenbacher delivered a report on the work of the Austrian Mathematical Society. Next, Stanislav Smirnov spoke about the Saint Petersburg Mathematical Society. Jorge Buesco talked about the Portuguese Mathematical Society, before Caroline Series presented a report on the EMS's newest member society, European Women in Mathematics. Thierry Horsin spoke about the work of the Société de Mathématiques Appliquées et Industrielles (SMAI), followed by Stéphane Seuret on the Société Mathématique de France.

Catalin Gherghe presented a short film about the International Mathematical Olympiad (IMO). The IMO started in 1959 in Romania and this July returned there for its 59th edition, with more than 2000 youngsters participating.

Klavdija Kutnar provided an update on preparations for the 8th European Congress of Mathematics to be held in Portorož (Slovenia), 5-11 July 2020. She especially drew attention to the open calls for Satellite Conferences and Minisymposia. 
Finally, Carlos Vázquez presented a report on preparations for the International Congress on Industrial and Applied Mathematics (ICIAM) in 2019 in Valencia (Spain).

\section{Discussion}

At every Presidents' meeting, time is set aside for open discussion. While participants are free to raise any topic (and do), it is helpful to have a theme for the conversation, which this time was the relationship between national societies and the EMS. There was extensive discussion about what should be done at a national level and what at the European level, and more generally how can we learn from and strengthen each other. It is not possible to summarise the entire discussion, but we mention a few items that were raised.

Firstly, the quality of mathematical high school education is a pan-European concern. Here, the EMS (and its Education committee in particular) can serve as a platform for the exchange of best practices.
In general, we should always seek maximise the use of EMS communication channels such as the E-news, to keep information flowing between national societies and the EMS. On a related point, the President conveyed a message from the Editor-in-Chief of the EMS Newsletter, Valentin Zagrebnov, that he would be pleased to receive proposals for articles.

The Presidents continued discussing assorted challenges, from the relationship between Mathematics and Computer Science to life-long learning opportunities for mathematics teachers.

After this lively and wide-ranging conversation, the Chair drew the meeting to a close, with enthusiastic thanks to the Irish Mathematical Society and, particularly Steve Buckley, for their excellent organization, and to Maynooth University for the friendly welcome to their beautiful campus. 